\title{
Prevalence of gastroenteritis among 4-year-old children in South Australia
}

\author{
J. S. HEYWORTH ${ }^{1 *}$, P. BAGHURST ${ }^{2}$ AND K. A. MCCAUL ${ }^{1}$ \\ ${ }^{1}$ School of Population Health, University of Western Australia, 35, Stirling Highway, Crawley 6009, \\ Western Australia \\ ${ }^{2}$ Women's and Children's Hospital, Adelaide and Department of Public Health and Department of Paediatrics, \\ The University of Adelaide
}

(Accepted 12 December 2002)

\section{SUMMARY}

The aim of this study was to determine the prevalence of gastroenteritis among children aged 4 years in South Australia. A cross-sectional survey of 9543 South Australian children aged 4 years was undertaken. Parents completed a questionnaire on behalf of their child who had attended a pre-school health check in 1998. The questionnaire covered gastrointestinal and respiratory symptoms experienced by the child in the previous 2 weeks and other risk factors for gastroenteritis. The 2-week prevalence of gastroenteritis among 4-year-old children was $14 \cdot 2 \%$. The major risk factors for gastroenteritis were presence of persons who had gastroenteritis inside the home, contact with persons who had gastroenteritis outside the home, antibiotic use and sore throat. Medical attention was sought for $20 \%$ of children who had gastroenteritis.

Gastroenteritis is a significant cause of morbidity among young children and presents a considerable burden on the community. A substantial proportion of these occurrences of highly credible gastrointestinal symptoms may be manifestations of respiratory infections.

\section{INTRODUCTION}

Gastroenteritis is a common cause of morbidity in young children. Studies from North America and elsewhere indicate that each year there are between $1 \cdot 2$ and $2 \cdot 5$ episodes of gastroenteritis per child aged 5 years or less [1-3]. Among persons of all ages, a recent randomized control trial in Melbourne, Australia found an incidence of gastroenteritis of 0.80 cases/person/year [4], whereas a longitudinal community study in the United Kingdom indicated a lower incidence of $0 \cdot 19 /$ person/year [5].

In the main, episodes of gastroenteritis are mild and self-limiting, but they are a source of substantial morbidity in the community and may result in serious dehydration or in long-term sequelae such as reactive

\footnotetext{
* Author for correspondence.
}

arthritis and haemolytic uraemic syndrome. In children gastroenteritis can be more severe. In the United States gastroenteritis accounts for $12 \%$ of hospital admissions for children aged 0-4 years [6]. In South Australia they account for $4 \cdot 2 \%$ of admissions. Barnes [7] estimated that for rotavirus infection alone, $50 \%$ of all Melbourne children require medical attention in their first 3 years of life. Episodes of gastroenteritis impact on daily activities of the child as well as their caregiver and can be a source of considerable discomfort. They are also potentially preventable.

Notification data provide an indication of the magnitude of the childhood gastroenteritis. In South Australia, notifications of infectious diseases show that the group at highest risk of gastroenteritis are the $0-4$ year-olds [8]. These data, however, are an underestimate of the prevalence of gastroenteritis in the community as not all infectious agents causing 
gastroenteritis are notifiable. For example, rotavirus infection, which is a common cause of gastroenteritis in children, is not notifiable [9]. The completeness of notification data is dependent on a number of factors: the affected child being taken to the doctor, a stool sample being taken, isolation of the causative organism and a report sent to the State Health Department. Furthermore, sporadic illnesses are less likely to be notified than those associated with a disease outbreak [10].

The aims of this study were to determine the prevalence of gastroenteritis among 4-year-old children in South Australia, and to describe the impact of gastroenteritis on daily activities of child and caregiver.

\section{METHODS}

This cross-sectional survey of 4-year-old children was undertaken in conjunction with the South Australian Child and Youth Health $(\mathrm{CYH})$ preschool health surveillance programme. $\mathrm{CYH}$ is a government agency with responsibility for health issues related to children and young people up to 24 years of age. Each year all children aged 4 years 3 months to 5 years old are invited by $\mathrm{CYH}$ to attend a pre-school health check at their kindergarten or child health centre. Approximately $80 \%$ of all South Australian preschool children attend a preschool health check [11].

To maintain confidentiality of the $\mathrm{CYH}$ clients, the investigators did not have direct contact with the clients. Instead the questionnaires were administered by $\mathrm{CYH}$ through the pre-schools. Throughout the 1998 school year, a 'gastroenteritis' questionnaire was attached to the $\mathrm{CYH}$ invitation for a pre-school health check. The questionnaire was sent to all parents of children aged 4 years 3 months to 5 years by the pre-school administrator. The parents were asked to return the completed questionnaire to the $\mathrm{CYH}$ at their child's preschool health check appointment. If they forgot to bring the questionnaire with them, the CYH nurse asked the parent to complete another if time permitted, or provided a reply-paid envelope for return of the questionnaire. The CYH nurses then returned completed questionnaires to the investigators.

The questionnaire covered gastrointestinal and respiratory symptoms experienced by the child in the previous 2 weeks, action taken as a result of gastrointestinal symptoms and exposure to potential risk factors preceding these symptoms. Questions about respiratory symptoms were included becuase gastrointestinal symptoms are frequently associated with respiratory illness [12]. Also included were questions on ongoing conditions or medical treatment that result in upset bowel actions or vomiting, and demographic information such as sex, aboriginality and area of residence. Socio-economic status (SES) was determined from the Socio-economic Index for Areas (SEIFA) [13]. This standardized index is derived from a range or variables related to poverty and disadvantage, including average income, educational level and housing type and provides a socio-economic classification by postcode. The questionnaire was piloted among parents of preschool children who attended a CYH preschool health check in December 1997.

\section{Definition of gastroenteritis}

The presence of highly credible gastrointestinal symptoms (HCGI) was used to define gastroenteritis. This definition was based upon that used by Payment et al. $[2,14]$ in their studies of drinking water and gastroenteritis. A HCGI episode was defined as one or more symptomatic days, involving at least one of the following combinations:

(1) Vomiting and/or liquid bowel movements, or

(2) Nausea and/or soft bowel movements combined with abdominal cramps.

The prevalence, rather than incidence, of gastroenteritis was determined, as a child may have had gastroenteritis that commenced prior to the 2-week recall period or may have had more than one episode of gastroenteritis in that period.

\section{Data analysis}

Data were coded and double entered for verification into a data file. Statistical analysis was undertaken using STATA [15]. All statistical tests and 95\% confidence intervals were estimated by robust methods that took into account the clustering in the data resulting from the inclusion of multiple births.

Logistic regression analysis was undertaken following the methods of Hosmer and Lemeshow [16]. For each risk factor, a univariate analysis of the association between HCGI as the dependent variable and the risk factor was undertaken. If the risk factor was significant at the conservative $P$-value of 0.25 or less it was included in the full model. The risk factors considered were sex, Aboriginality, child care, 
Table 1. Demographic characteristics of 4-year-old participants, South Australia $1998(n=9543)$

\begin{tabular}{lrr}
\hline \hline & $n^{*}$ & $\%$ \\
\hline Sex & & \\
$\quad$ Male & 4886 & $51 \cdot 3$ \\
$\quad$ Female & 4639 & $48 \cdot 7$ \\
Area of residence $\dagger$ & & \\
$\quad$ Metropolitan Adelaide & 6653 & $69 \cdot 1$ \\
$\quad$ Rural South Australia & 2867 & $30 \cdot 1$ \\
Aboriginal or Torres Strait Islander & & \\
$\quad$ Yes & 154 & $1 \cdot 6$ \\
$\quad$ No & 9325 & $98 \cdot 4$ \\
Socio-economic status $\dagger$ & & \\
1 (Low) & 1601 & $16 \cdot 8$ \\
2 & 4181 & $44 \cdot 0$ \\
3 & 1645 & $17 \cdot 3$ \\
4 (High) & 2084 & $21 \cdot 9$ \\
\hline \hline
\end{tabular}

* Missing values lead to some variations in the category totals. The proportion of missing values range from $0 \cdot 19 \%$ (18) to $0.67 \%$ (64).

$\dagger$ Eight respondents from the state of Victoria were not classified.

attendance at kindergarten, earache, sore throat, cold or influenza, hay fever, other allergy, antibiotic use, vaccination, area of residence, number of children in the household, socio-economic status, pets, contact with farm animals, swimming and contact with a person who had vomited or had diarrhoea. Month was included to adjust for the seasonal variation in gastroenteritis.

\section{RESULTS}

During 1998, 14030 children aged 4 years 3 months to 5 years received a health check. Of these $926(6 \cdot 6 \%)$ were of a non-English speaking background (personal communication $\mathrm{CYH}, 2000)$ and hence ineligible. Questionnaires were returned for 9543 children giving a response rate of $72 \cdot 8 \%$.

Table 1 shows the demographic characteristics of all children participating in this study. Thirty per cent of the participants were rural children, reflecting the distribution of the population across the State [17]. The socio-economic status of the participants of the study was similar to that for all 4-year-olds: $18.9 \%$ were of low SES $; 45.6 \%$ SES $2 ; 15.5 \%$ SES 3 ; and $19 \cdot 7 \%$ high SES. This distribution was determined by using the socio-economic status of children born in 1994 and hence 4 years old in 1998. Aboriginal and Torres Strait Islander children were under-represented in the sample. In the South
Table 2. Two-week prevalence of gastrointestinal and respiratory illness amongst 4-year-old children, South Australia $(n=9233)$

\begin{tabular}{lrrc}
\hline \hline & $n$ & $\%$ & $95 \%$ CI \\
\hline Gastro-intestinal symptoms & & & \\
$\quad$ Vomiting & 768 & $8 \cdot 3$ & $7 \cdot 8-8 \cdot 9$ \\
$\quad$ Soft bowel actions & 1295 & $14 \cdot 4$ & $13 \cdot 7-15 \cdot 1$ \\
Liquid bowel actions & 323 & $3 \cdot 6$ & $3 \cdot 2-4 \cdot 0$ \\
Nausea & 878 & $9 \cdot 2$ & $8 \cdot 5-9 \cdot 7$ \\
Stomach cramps & 837 & $9 \cdot 6$ & $9 \cdot 0-10 \cdot 3$ \\
Fever & 1124 & $12 \cdot 3$ & $11 \cdot 6-13 \cdot 0$ \\
HCGI & 1263 & $14 \cdot 2$ & $13 \cdot 5-14 \cdot 9$ \\
Respiratory illness & & & \\
$\quad$ Cold or influenza & 3108 & $34 \cdot 0$ & $33 \cdot 0-34 \cdot 9$ \\
Sore throat & 1760 & $19 \cdot 3$ & $18 \cdot 5-20 \cdot 1$ \\
$\quad$ Ear infection & 647 & $7 \cdot 0$ & $6 \cdot 5-7 \cdot 6$ \\
\hline \hline
\end{tabular}

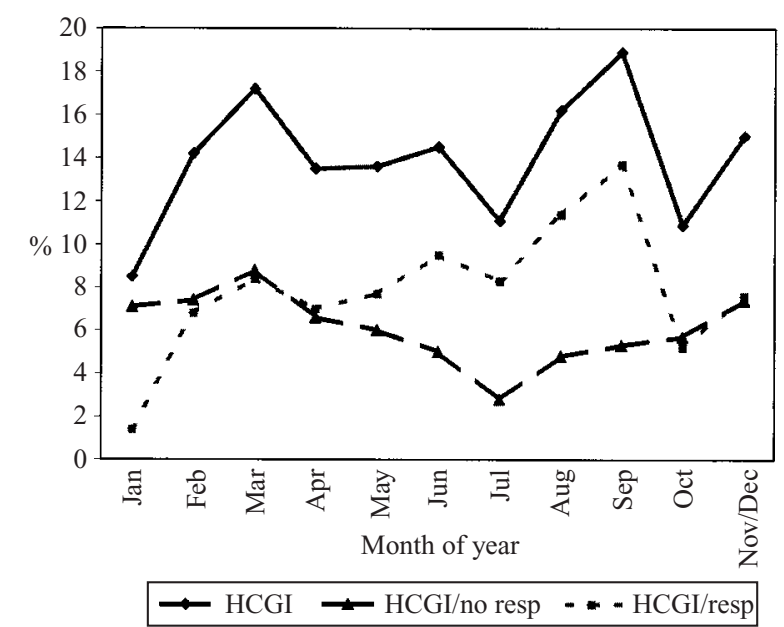

Fig. 1. Prevalence of total HCGI, respiratory-related HCGI, non-respiratory-related HCGI and respiratory illness without HCGI among 4-year-old children by month, South Australia. December and November data were combined because of the small numbers of health checks conducted in December.

Australian population, $3 \%$ of all children aged 0-4 years were of Aboriginal or Torres Strait Islander descent [18].

Those children who had a medical condition or treatment that resulted in upset bowel actions or vomiting $(n=283)$ were excluded from further analysis. In addition, 19 whose children had returned from overseas travel in the last 2 weeks and 8 respondents who resided in Victoria were excluded. Thus subsequent analyses reflect data for 9233 children.

The 2-week prevalence rates of gastrointestinal and respiratory symptoms and HCGI are shown in Table 2. Overall there were 1263 children with HCGI 
Table 3. Logistic regression analysis: risk factors for HCGI $(n=8379)$

\begin{tabular}{|c|c|c|c|c|}
\hline Variable & $n$ & $\begin{array}{l}\text { Unadjusted } \\
\text { Odds Ratio } \\
(95 \% \mathrm{CI})\end{array}$ & $\begin{array}{l}\text { Adjusted } \\
\text { Odds Ratio } \\
(95 \% \mathrm{CI})\end{array}$ & $\begin{array}{l}P \text {-value for } \\
\text { adjusted OR }\end{array}$ \\
\hline \multicolumn{5}{|c|}{ Presence of a person who had vomited or had loose bowel actions in last 2 weeks inside home } \\
\hline No & 6815 & $1 *$ & 1 & \\
\hline Yes & 1564 & $\begin{array}{l}4 \cdot 48 \\
(3 \cdot 02,5 \cdot 12)\end{array}$ & $\begin{array}{l}3 \cdot 47 \\
(3 \cdot 00,4 \cdot 01)\end{array}$ & $<0 \cdot 001$ \\
\hline \multicolumn{5}{|c|}{ Contact outside home with person who had vomiting or loose bowel actions in last 2 weeks } \\
\hline No & 5176 & 1 & 1 & \\
\hline Don’t know & 2405 & $\begin{array}{l}2 \cdot 37 \\
(2 \cdot 06,2 \cdot 72)\end{array}$ & $\begin{array}{l}1 \cdot 91 \\
(1 \cdot 65,2 \cdot 22)\end{array}$ & $<0 \cdot 001$ \\
\hline Yes & 798 & $\begin{array}{l}3 \cdot 86 \\
(3 \cdot 21,4 \cdot 63)\end{array}$ & $\begin{array}{l}2 \cdot 33 \\
(1 \cdot 91,2 \cdot 84)\end{array}$ & $<0 \cdot 001$ \\
\hline \multicolumn{5}{|c|}{ Antibiotics in the last 2 weeks } \\
\hline No & 7552 & 1 & 1 & \\
\hline Yes & 827 & $\begin{array}{l}2 \cdot 73 \\
(2 \cdot 31,3 \cdot 23)\end{array}$ & $\begin{array}{l}2 \cdot 06 \\
(1 \cdot 66,2 \cdot 58)\end{array}$ & $<0 \cdot 001$ \\
\hline \multicolumn{5}{|l|}{ Sore throat in last 2 weeks } \\
\hline No & 6804 & 1 & 1 & \\
\hline Yes & 1575 & $\begin{array}{l}2 \cdot 42 \\
(2 \cdot 11,2 \cdot 78)\end{array}$ & $\begin{array}{l}1 \cdot 86 \\
(1 \cdot 58,2 \cdot 20)\end{array}$ & $<0 \cdot 001$ \\
\hline \multicolumn{5}{|l|}{ Hay fever in last 2 weeks } \\
\hline No & 7947 & 1 & 1 & \\
\hline Yes & 432 & $\begin{array}{l}0.68 \\
(0.49,0.94)\end{array}$ & $\begin{array}{l}0 \cdot 58 \\
(0 \cdot 41,0 \cdot 81)\end{array}$ & $0 \cdot 002$ \\
\hline \multicolumn{5}{|c|}{ Unpasteurized milk or cream } \\
\hline No & 8232 & 1 & 1 & \\
\hline Regular consumer & 119 & $\begin{array}{l}0 \cdot 33 \\
(0 \cdot 15,0 \cdot 75)\end{array}$ & $\begin{array}{l}0 \cdot 32 \\
(0 \cdot 14,0 \cdot 75)\end{array}$ & $0 \cdot 01$ \\
\hline One-off in last 2 weeks & 28 & $\begin{array}{l}2 \cdot 49 \\
(1 \cdot 09,5 \cdot 67)\end{array}$ & $\begin{array}{l}2 \cdot 93 \\
(1 \cdot 22,7 \cdot 05)\end{array}$ & $0 \cdot 02$ \\
\hline \multicolumn{5}{|l|}{ Earache } \\
\hline No & 7821 & 1 & 1 & \\
\hline Yes & 558 & $\begin{array}{l}2 \cdot 43 \\
(1 \cdot 99,2 \cdot 96)\end{array}$ & $\begin{array}{l}1 \cdot 28 \\
(0 \cdot 99,1 \cdot 66)\end{array}$ & $0 \cdot 06$ \\
\hline \multicolumn{5}{|l|}{ Attendance at kindergarten } \\
\hline No & 350 & 1 & 1 & \\
\hline Yes & 8029 & $\begin{array}{l}0 \cdot 75 \\
(0 \cdot 56,0 \cdot 99)\end{array}$ & $\begin{array}{l}0 \cdot 76 \\
(0 \cdot 59,1 \cdot 10)\end{array}$ & $0 \cdot 18$ \\
\hline \multicolumn{5}{|c|}{ Attendance at child care centre } \\
\hline No & 7336 & 1 & 1 & \\
\hline Yes & 1069 & $\begin{array}{l}1 \cdot 30 \\
(1 \cdot 08-1 \cdot 56)\end{array}$ & $\begin{array}{l}1 \cdot 12 \\
(0 \cdot 92,1 \cdot 36)\end{array}$ & $0 \cdot 25$ \\
\hline \multicolumn{5}{|c|}{ Regular contact with farm animals } \\
\hline No & 7419 & 1 & 1 & \\
\hline Yes & 960 & $\begin{array}{l}1 \cdot 19 \\
(0 \cdot 98,1 \cdot 43)\end{array}$ & $\begin{array}{l}1 \cdot 18 \\
(0 \cdot 96,1 \cdot 44)\end{array}$ & $0 \cdot 11$ \\
\hline \multicolumn{5}{|c|}{ Swimming in the last 2 weeks } \\
\hline No & 5639 & 1 & 1 & \\
\hline Yes & 2740 & $\begin{array}{l}1 \cdot 13 \\
(0 \cdot 99,1 \cdot 29)\end{array}$ & $\begin{array}{l}1 \cdot 10 \\
(0 \cdot 94,1 \cdot 28)\end{array}$ & $0 \cdot 20$ \\
\hline \multicolumn{5}{|l|}{ Socio-economic status } \\
\hline Lowest & 1377 & $\begin{array}{l}0.90 \\
(0 \cdot 74,1 \cdot 09)\end{array}$ & $\begin{array}{l}0 \cdot 88 \\
(0 \cdot 70,1 \cdot 10)\end{array}$ & $0 \cdot 26$ \\
\hline Lower middle & 3685 & $\begin{array}{l}1 \cdot 04 \\
(0 \cdot 89,1 \cdot 20)\end{array}$ & $\begin{array}{l}1 \cdot 09 \\
(0 \cdot 92,1 \cdot 30)\end{array}$ & $0 \cdot 32$ \\
\hline
\end{tabular}


Table 3. (cont.)

\begin{tabular}{|c|c|c|c|c|}
\hline Variable & $n$ & $\begin{array}{l}\text { Unadjusted } \\
\text { Odds Ratio } \\
(95 \% \mathrm{CI})\end{array}$ & $\begin{array}{l}\text { Adjusted } \\
\text { Odds Ratio } \\
(95 \% \text { CI })\end{array}$ & $\begin{array}{l}P \text {-value for } \\
\text { adjusted OR }\end{array}$ \\
\hline Upper middle & 1462 & $\begin{array}{l}0.87 \\
(0 \cdot 72,1 \cdot 04)\end{array}$ & $\begin{array}{l}0 \cdot 88 \\
(0 \cdot 71,1 \cdot 10)\end{array}$ & $0 \cdot 26$ \\
\hline Highest & 1855 & 1 & 1 & \\
\hline \multicolumn{5}{|c|}{ No. of other children $\leqslant 4$ years in home } \\
\hline 0 or 1 & 7697 & 1 & 1 & \\
\hline 2 or more & 682 & $\begin{array}{l}1 \cdot 20 \\
(0 \cdot 97,1 \cdot 49)\end{array}$ & $\begin{array}{l}1 \cdot 07 \\
(0 \cdot 84,1 \cdot 36)\end{array}$ & 0.55 \\
\hline \multicolumn{5}{|l|}{ Allergy } \\
\hline No & 8042 & 1 & 1 & \\
\hline Yes & 337 & $\begin{array}{l}1 \cdot 21 \\
(0 \cdot 90,1 \cdot 63)\end{array}$ & $\begin{array}{l}1 \cdot 07 \\
(0 \cdot 77,1 \cdot 49)\end{array}$ & $0 \cdot 68$ \\
\hline \multicolumn{5}{|c|}{ Cold or 'flu' in last 2 weeks } \\
\hline No & 5590 & 1 & 1 & \\
\hline Yes & 2789 & $\begin{array}{l}1 \cdot 45 \\
(1 \cdot 28,1 \cdot 65)\end{array}$ & $\begin{array}{l}0 \cdot 99 \\
(0 \cdot 85,1 \cdot 15)\end{array}$ & $0 \cdot 87$ \\
\hline
\end{tabular}

* Model also adjusted for month (see Fig. 1).

giving a prevalence of $14 \cdot 2 \%(95 \%$ CI $13 \cdot 5,14 \cdot 9)$. The prevalence of HCGI was the same in the metropolitan and rural areas.

Of the 1263 cases of HCGI, $716(56.7 \%)$ also reported the presence of respiratory symptoms in the last 2 weeks. The most commonly reported condition was cold or influenza with one-third of all children reported to have had a cold or influenza in the last 2 weeks. The prevalence measures of all symptoms/ conditions were similar in metropolitan Adelaide and rural South Australia, except for cold or influenza. The 2-week prevalence of cold or influenza was significantly higher among rural South Australians $(37 \cdot 3 \%)$ compared with Adelaide (32.5\%).

The prevalence by month of HCGI overall, and with and without respiratory symptoms, in the same 2-week period are shown in Figure 1. The association between respiratory conditions and HCGI was greatest through winter and spring, particularly during the spring peak in September.

The results of the logistic regression analysis are shown in Table 3. The factors that were significantly associated with an increased risk of HCGI were each of the following in the previous 2 weeks: antibiotic use, sore throat, presence of a person who had vomiting and/or loose bowel actions in the home, and contact outside the home with a person who had vomiting and/or loose bowel actions. The attributable fractions of gastroenteritis associated with each of these factors were $7 \cdot 7,11 \cdot 6,26 \cdot 0$ and $15 \cdot 7 \%$ respectively.
A child who had drunk unpasteurized milk in the last 2 weeks but did not normally drink unpasteurized milk, was at greater risk of HCGI whereas those children who normally drank unpasteurized milk had a reduced risk of HCGI. Month of the year was also significantly associated with HCGI. Hay fever in the last 2 weeks was associated with a reduced risk of HCGI.

The model also included attendance at kindergarten, attendance at child care centres, regular contact with farm animals, swimming in the last 2 weeks, socio-economic status, number of children aged 4 years or less in the home, allergy and cold or influenza in the last 2 weeks. None of these factors was significantly associated with HCGI after adjustment for other covariates (Table 3).

\section{Action as a result of HCGI}

Among the 1263 children who were reported to have had HCGI in the previous 2 weeks, $259(20.5 \%)$ were taken to see a doctor and $8(0.6 \%)$ were admitted to hospital (Table 4); $26 \%$ of children stayed in bed for 1 or more days. The median number of days spent in bed was 1 day and the maximum was 14 days. The number of adults who took time off work was 206 $(16 \cdot 3 \%)$. Fifty-two parents indicated an additional action/s had occurred as a result of the HCGI episode. Thirty-one of these parents indicated that their child rested at home or was monitored, rather 
Table 4. Action taken as a result of HCGI symptoms in previous 2 weeks, 4-year-old children with HCGI, South Australia $(n=1263)$

\begin{tabular}{lrr}
\hline \hline Action as a result of HCGI $^{*}$ & \multicolumn{1}{c}{ \% } \\
\hline Child saw general practitioner & 259 & $20 \cdot 5$ \\
$\quad$ or hospital doctor & 8 & $0 \cdot 6$ \\
Child admitted to hospital & 64 & $5 \cdot 1$ \\
Advice sought from chemist or CYH & 344 & $26 \cdot 4$ \\
Child stayed in bed & 266 & $21 \cdot 1$ \\
$\quad$ For 1-2 days & 29 & $2 \cdot 3$ \\
For 3-5 days & 16 & $1 \cdot 3$ \\
For 6 or more days & 33 & $2 \cdot 6$ \\
not stated & 206 & $16 \cdot 3$ \\
Adult took time off work & 143 & $11 \cdot 3$ \\
For 1-2 days & 36 & $2 \cdot 8$ \\
For 3-5 days & 11 & $0 \cdot 1$ \\
For 6 or more days & 16 & $1 \cdot 3$ \\
not stated & 52 & $4 \cdot 1$ \\
Other & \\
\hline \hline
\end{tabular}

* Categories were not mutually exclusive.

than stayed in bed. Three parents rang their doctor or hospital for advice. Four parents gave herbal medicine/consultation and another five gave over-thecounter medicine. Six indicated that they limited their child's dairy intake. The remaining three parents did one of the following: increased fluids; gave yoghurt; or made plans to take their child to the doctor.

For children reported to have loose bowel actions or vomiting, parents were asked if these symptoms were preceded by other biomedical factors. The most common factors identified by parents as preceding a child's HCGI episode were: first, a cold, influenza or earache $(27 \%)$; second and third, contact inside $(18 \%)$ or outside $(13 \%)$ the home with persons who had vomited or had loose bowel actions; and fourth, taking medication $(9 \%)$.

\section{DISCUSSION}

\section{Prevalence of gastroenteritis among 4-year-olds}

The prevalence of gastroenteritis observed in this study was higher than the rates observed in earlier studies $[2,3,12,19]$. In this study, for every 100 children, 14 had suffered from HCGI in the last 2 weeks, although often in conjunction with respiratory symptoms. In a prospective study of the impact of drinking water on endemic gastrointestinal disease in Canada, the number of HCGI episodes in the 2-5 year age group was 1.3 episodes per person-year among consumers of mains supply tap water [2]. This equates approximately to a 2 -week prevalence of $5 \cdot 4 \%$. Similarly the 2-week prevalence of gastroenteritis estimated from a longitudinal study in the United States [12] was $6 \%$ for children aged 3-4 years.

Fifty-seven per cent of the children who were reported to have HCGI, had also experienced respiratory illness in the previous 2 weeks. While from a cross-sectional survey such as this, it is not possible to know whether the gastrointestinal symptoms were related to the respiratory illness, the results are consistent with such a relationship. Monto and Koopman [12] estimated that between 27 and $44 \%$ of all enteric illness were related to respiratory illness.

The higher rates of HCGI observed in this study may be genuine, but they may also reflect recall bias, differences in the definition of gastroenteritis or sampling or response bias. Recall of symptoms over a 2-week period may have resulted in 'telescoping' of symptoms, that is, symptoms that occurred approximately 15-17 days ago were recalled as occurring within the more recent past. Consistent with telescoping, higher rates gastroenteritis rates in England were determined from retrospective assessment compared with rates determined prospectively [51]. In the studies by Monto and Koopman [12] and Payment et al. [2], gastrointestinal symptom data were collected via a diary over a $12-18$ month period hence reducing recall bias.

Because the aim of the study reported here was to determine the endemic prevalence of gastroenteritis from the mild to more severe cases, the definition in this study was chosen to maximize its sensitivity. However, this may have been at the expense of specificity. Other studies have used diarrhoea rather than soft or liquid bowel movements in the definition of HCGI [2, 12, 20]. However, self-reporting of diarrhoea relies on the interpretation of this term by respondents. In this study soft and liquid bowel actions were used as a more neutral term to increase the sensitivity of identifying gastroenteritis. This may well have led to an overestimation of gastroenteritis in relation to one soft bowel action; however, stomach cramps also had to be present for a classification of HCGI. It was not practical to ask respondents to recall the number of soft or liquid bowel actions in any one $24 \mathrm{~h}$ period within a 2 -week recall period.

HCGI weights the definition towards vomiting and liquid diarrhoea with the presence of these symptoms included in $61 \%$ and $20 \%$ of all HCGI respectively. Hence HCGI is predominantly a reflection of the presence of these two symptoms, in particular vomiting. 
Yet these symptoms may be symptomatic of a broad range of illnesses other than gastroenteritis. To a certain extent this issue was addressed in the design, by excluding those children who had an illness or medical treatment for which vomiting or loose bowel action were symptoms. However, this exclusion was limited to chronic illnesses or treatments.

Obtaining a sampling frame for this age is difficult, but the CYH pre-school health check provided the best opportunity to survey young children. However, approximately $20 \%$ of children did not attend for a health check. Our data indicate that Aboriginal children are under-represented and $\mathrm{CYH}$ indicated that some parents do not attend for religious or cultural reasons. Rates of gastroenteritis are higher among Aboriginal children [21, 22]. While they are a small proportion of the overall population, their underrepresentation may have biased the estimate of HCGI prevalence downwards.

Twenty-seven per cent of parents did not return the questionnaire. While the response fraction was reasonable given the convoluted process of questionnaire administration, there was the potential that this $27 \%$ represented a group of children at a lesser risk of HCGI. Parents of children with a recent history of HCGI may well have been more likely to complete the questionnaire.

\section{Risk factors for gastroenteritis}

Not surprisingly the risk factors that increased the odds of HCGI to the greatest extent were: presence of a person who had vomited or had loose bowel actions within the home; contact outside the home with a person who had vomited or had loose bowel actions; antibiotic usage; time of year; and one-off consumption of unpasteurized milk. Person-to-person transmission of gastroenteritis is a common route of transmission [23-25]. In this study the presence of a person with gastroenteritis may indicate either person-to-person transmission or simultaneous exposure to a point source. In a study of gastroenteritis amongst bathers, Kay et al. [23] found that prior gastroenteritis in a family member was a significant risk factor, (Odds Ratio $=4 \cdot 4$, 95\% CI 1·3-14.6). Potentially there is an opportunity through health education, to reduce the spread of gastroenteritis among family members.

Antibiotic-associated diarrhoea is a well-recognized phenomenon [26]. In this study antibiotic use was associated with a twofold increase in the odds of reporting HCGI. While the use of antibiotics may be necessary, potentially there are opportunities to reduce the prevalence of diarrhoea in terms of both choice and over-prescribing of antibiotics.

The relationship between gastroenteritis and the consumption of unpasteurized milk raises the question of whether or not immunity develops among regular consumers of unpasteurized milk. A similar finding was observed by Blaser et al. [27]. In an investigation of an outbreak of campylobacterosis among persons attending a fraternity retreat, none of the persons who were regular consumers of raw milk became ill, whereas among the other non-regular consumers the attack rate was $76 \%$ [27].

Peaks in HCGI prevalence were observed in early autumn and early spring. Both HCGI without respiratory symptoms and HCGI with respiratory symptoms contributed to the autumn peak, whereas the spring peak predominantly reflects an increase in HCGI associated with respiratory symptoms. This pattern differs from what is normally described in the literature. A winter peak is associated often with rotavirus infections and a summer peak is associated with bacterial infections [24, 25, 28, 29]. However, as these children are aged 4 years, they are past the high risk age group (up to age 3 years) for rotavirus and thus a winter peak may be less apparent. Considering only the HCGI without respiratory symptoms, a higher prevalence is observed over spring and summer with decline over the autumn/winter months.

\section{Hay fever}

The reduction in risk associated with hay fever was an unexpected finding. There is some evidence that exposure to infection in early childhood is protective against later atopy and asthma by enhancing Th 1 immunity [30]. This finding raises the question as to whether or not current episodes of gastroenteritis also protect against hay fever episodes, or vice versa. Alternatively this association may be an artefact of multiple comparisons. Further investigation of this hypothesis has been incorporated into the design of a longitudinal study of gastroenteritis among young children.

\section{Attendance at child care centres}

The lack of association between HCGI and attendance at child care is not surprising. While there is some evidence that attendance at child care may 
increase the risk of gastrointestinal symptoms, this appears to be limited to children aged less than 3 years [31-34].

\section{Responses to gastroenteritis}

Twenty per cent of children with symptoms of vomiting or loose bowel actions saw a doctor as a result of these symptoms. Herkistad et al. [3] reported a similar percentage, $23 \%$ of $0-4$ year old children were taken to see a doctor, whereas Monto and Koopman [12] reported a higher percentage, $29 \%$. Thus in Australia for 4 year olds alone $(n=262481)$ it is estimated, based on these South Australian data, that each fortnight there are 7641 GP visits for gastroenteritis, 9840 child-days in bed and 6073 adult days off work. The vast majority of children, however, were not greatly affected; $73.6 \%$ did not need to stay in bed, but simply rested at home or recovered in less than 1 day.

\section{CONCLUSION}

In conclusion, gastroenteritis is a significant cause of morbidity amongst young children. In this study to date $14 \cdot 2 \%$ were reported to have had gastroenteritis in the previous 2 weeks. While a substantial proportion of these occurrences of HCGI may be manifestations of respiratory infections, and while they are often mild, these illnesses still contribute a considerable burden on families and the health care system.

\section{ACKNOWLEDGMENTS}

The invaluable assistance of Child and Youth Health, in particular the nurses involved with the pre-school health check, and also the kindergarten and pre-school directors is gratefully acknowledged. Dr A. Chan, Pregnancy Outcome Unit of the South Australian Department of Human Services is acknowledged for providing the postcode frequency distribution for children born in 1994. The financial support of the South Australian Department of Human Services for this project is also gratefully acknowledged.

\section{REFERENCES}

1. Glass R, Lew J, Gangarosa R, LeBaron C, Ho M. Estimates of morbidity and mortality rates for diarrheal diseases in American children. J Pediatr 1991; 118: S27-33.
2. Payment P, Siemiatycki J, Richardson L, et al. A prospective epidemiological study of gastro-intestinal health effects due to the consumption of drinking water. Int J Environ Hlth Res 1997; 7: 5-31.

3. Herikstad H, Yang S, Van Gilder TJ, et al. A population-based estimate of the burden of diarrhoeal illness in the United States: FoodNet, 1996-7. Epidemiol Infect 2002; 129: 9-17.

4. Hellard ME, Sinclair MI, Forbes AB, Fairley CK. A randomized, blinded, controlled trial investigating the gastrointestinal health effects of drinking water quality. Environ Health Perspect 2001; 109: 773-8.

5. Wheeler J, Sethi D, Cowden J, et al. Study of infectious intestinal disease in England: rates in the community, presenting to general practice and reported to national surveillance. BMJ 1999; 318: 1046-50.

6. Jin S, Kilgore P, Holman R, et al. Trends in hospitalisations for diarrhea in United States children from 1979 through 1992: estimates of the morbidity associated with rotavirus. Pediatr Infect Dis J 1996; 15: 397-404.

7. Barnes GL, Uren E, Stevens KB, Bishop RF. Etiology of acute gastroenteritis in hospitalized children in Melbourne, Australia, from April 1980 to March 1993. J Clin Microbiol 1998; 36: 133-8.

8. Communicable Disease Control Branch. Infectious and notifiable disease in South Australia: Annual Summary 1993 and 1994. Adelaide: SAHC, 1996.

9. Ferson M. Hospitalisations for rotavirus gastroenteritis among children under five years of age in New South Wales. Med J Aust 1996; 164: 273-7.

10. Morris R, Levin R. Estimating the incidence of waterborne infectious disease related to drinking water in the United States. Assessing and managing health risks from drinking water contamination: approaches and applications: IAHS Publ no 233, 1994 : 75-88.

11. Volkmer R, Ruffin R, Wigg N, Davies N. The prevalence of respiratory symptoms in South Australian preschool children. 1. Geographic location. J Paediatr Child Hlth 1995 ; 31 : 112-5.

12. Monto A, Koopman J. The Tecumseh study, XI. Occurrence of acute enteric illness in the community. Am J Epidemiol 1980; 112: 323-33.

13. McLennan W. Information paper: census of population and housing-socio-economic indexes for areas, Australia, 2039.0. Canberra: Australian Bureau Of Statistics, 1998.

14. Payment P, Richardson L, Siemiatycki J, et al. A randomised trial to evaluate the risk of gastro-intestinal disease due to consumption of drinking water meeting current microbiological standards. Am J Publ Hlth 1991; 81: 703-8.

15. Stata Corp. Stata Statistical Software. College Station, Texas: Stata Corporation, 1999.

16. Hosmer D, Lemeshow S. Applied logistic regression. New York: John Wiley \& Sons, 1989.

17. Crettenden I. Population by age and sex, South Australia. Canberra: Australian Bureau of Statistics, 1999. 
18. McLennan W. Population Distribution: Indigenous Populations 1996, 4705.0. Canberra: Australian Bureau of Statistics, 1997.

19. Stone DH, Mitchell S, Packham B, Williams J. Prevalence and first-line treatment of diarrhoeal symptoms in the community. Publ Hlth $1994 ; 108$ : $61-8$.

20. Cabelli V, Dufour A, Levin M, McCabe L, Haberman P. Relationship of microbial indicators to health effects at marine bathing beaches. Am J Publ Hlth 1979; 69: 690-6.

21. Gracey M, Dennison M, Burke V. Hospital admissions of Aborigines and non-Aborigines in Western Australia, 1977-1988. Trans R Soc Trop Med Hyg 1992; 86: 694-7.

22. Gunzburg S, Gracey M, Burke V, Chang B. Epidemiology and microbiology of diarrhoea in young Aboriginal children in the Kimberley region of Western Australia. Epidemiol Infect 1992; 108: 67-76.

23. Kay D, Fleisher J, Salmon R, et al. Predicting likelihood of gastroenteritis from sea bathing: results from randomised exposure. Lancet 1994; 344: 905-9.

24. Kotloff K, Wasserman S, Steciak J, et al. Acute diarrhoea in Baltimore children attending an outpatient clinic. Pediatr Infect Dis J 1988; 7: 752-9.

25. Uhnoo I, Wadell G, Svensson L, et al. Aetiology and epidemiology of acute gastroenterits in Swedish children. J Infect 1986; 13: 73-89.
26. McFarland LV. Epidemiology, risk factors and treatments for antibiotic-associated diarrhea. Digest Dis 1998; 16: 292-307.

27. Blaser M, Sazie E, Williams L. The influence of immunity on raw milk-associated campylobacter infection. JAMA 1987; 257: 43-6.

28. Crowley D, Ryan M, Wall P. Gastroenteritis in children under 5 years of age in England and Wales. CDR 1997; 7: R82-R6.

29. Caprioli A, Pezzella C, Morelli R, et al. Enteropathogens associated with childhood diarrhoea in Italy. Pediatr Infect Dis J 1996; 15: 876-83.

30. Holt P. Infections and the development of allergy. Toxicol Lett 1996; 86: 205-10.

31. Staat M, Morrow A, Reves RR, Bartlett AV, Pickering LK. Diarrhea in children newly enrolled in day-care centers in Houston. Pediatr Infect Dis J 1991 ; 10 : 282-6.

32. Sullivan P, Woodward WE, Pickering LK, DuPont HL. Longitudinal study of occurrence of diarrhoeal disease in day care centres. Am J Publ Hlth 1984; 74: 987-91.

33. Reves R, Morrow A, Bartlett AV, et al. Child day care increases the risk of clinic visits for acute diarrhoea and diarrhoea due to rotavirus. Am J Epidemiol 1993; 137: 97-107.

34. Alexander C, Zinzeleta E, MacKenzie EJ, Vernon A, Markowitz RK. Acute gastrointestinal illness and child care arrangements. Am J Epidemiol 1990; 131 : 124-31. 